Provided for non-commercial research and education use. Not for reproduction, distribution or commercial use.

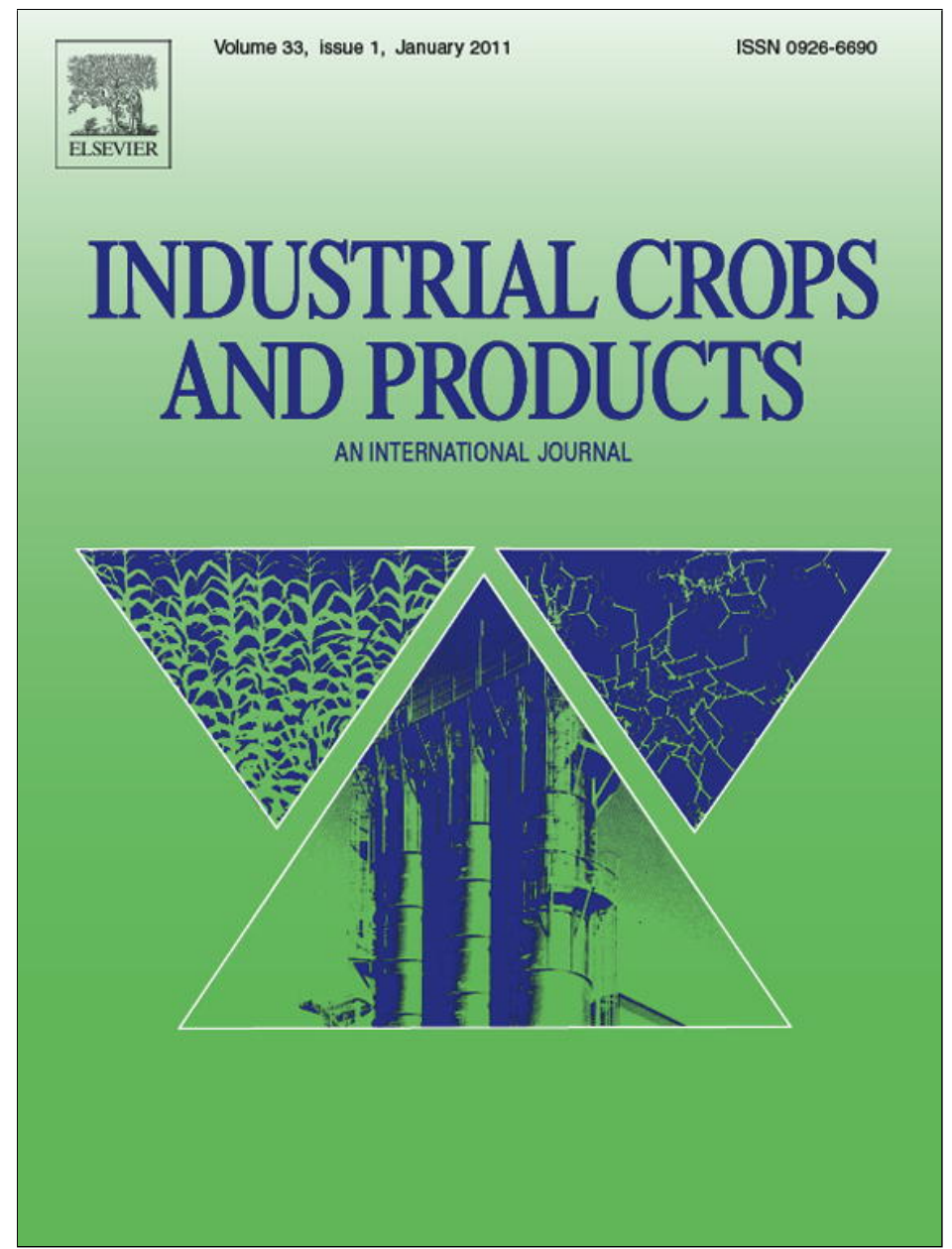

(This is a sample cover image for this issue. The actual cover is not yet available at this time.)

This article appeared in a journal published by Elsevier. The attached copy is furnished to the author for internal non-commercial research and education use, including for instruction at the authors institution and sharing with colleagues.

Other uses, including reproduction and distribution, or selling or licensing copies, or posting to personal, institutional or third party websites are prohibited.

In most cases authors are permitted to post their version of the article (e.g. in Word or Tex form) to their personal website or institutional repository. Authors requiring further information regarding Elsevier's archiving and manuscript policies are encouraged to visit:

http://www.elsevier.com/copyright 


\title{
Evaluation of a phenological model for strategic decisions for hemp (Cannabis Sativa L.) biomass production across European sites
}

\author{
Stefano Amaducci ${ }^{\mathrm{a}, *}$, Michele Colauzzi ${ }^{\mathrm{b}}$, Gianni Bellocchi ${ }^{\mathrm{c}}$, Salvatore Luciano Cosentino ${ }^{\mathrm{d}}$, \\ Katri Pahkala ${ }^{\mathrm{e}}$, Tjeerd Jan Stomph ${ }^{\mathrm{f}}$, Wim Westerhuis ${ }^{\mathrm{f}}$, Alessandro Zatta ${ }^{\mathrm{b}}$, Gianpietro Venturi ${ }^{\mathrm{b}}$ \\ ${ }^{a}$ Institute of Agronomy and Crop Science, Università Cattolica del Sacro Cuore, 29122 Piacenza, Italy \\ ${ }^{\mathrm{b}}$ Department of Agroenvironmental Science and Technology, University of Bologna, 40137 Bologna, Italy \\ ${ }^{\mathrm{c}}$ Research Institute for Industrial Crops, Agricultural Research Council, 40128 Bologna, Italy \\ d Institute of Agronomy and Crop Science, University of Catania, 95123 Catania, Italy \\ e Agrifood Research Finland, Plant Production Research, Crops and Biotechnology, 31600 Jokioinen, Finland \\ ${ }^{\mathrm{f}}$ Wageningen University, Crop and Weed Ecology Group, 6700AK Wageningen, The Netherlands
}

\section{A R T I C L E I N F O}

\section{Article history:}

Received 11 April 2011

Received in revised form 28 October 2011

Accepted 14 November 2011

\section{Keywords:}

Hemp (Cannabis sativa L.)

Modelling

Parameterization

Phenology

Photo-period

\begin{abstract}
A B S T R A C T
The optimal combination of yield and quality of hemp fibres from field grown crops is around flowering. Therefore prediction of flowering time would support in planning production and optimization of the cultivar choice for different agro-ecological zones. In the current paper the validation of a recently published model (Amaducci et al., 2008a) is carried out for four varieties across a wide range of sites and thus of air temperature-photoperiod combinations. The model was evaluated by comparing its output to field observations of the duration between emergence and 50\% flowering. The model output and observed times from emergence to $50 \%$ of flowering generally corresponded well, but some discrepancies were apparent. The biggest discrepancies between estimates and actual data were observed at extreme latitudes. The level of accuracy of the model predictions is satisfactory for strategic decision regarding sowing and harvesting time and cultivar choice, but tactical decisions (e.g. time of harvest based on flowering time) cannot be accurately supported.
\end{abstract}

(c) 2011 Elsevier B.V. All rights reserved.

\section{Introduction}

Hemp (Cannabis sativa L.) is a crop traditionally grown for its long bast fibres and for the seeds, though it can also be grown for its short fibres (Karus, 2002) or for energy production (Biewinga and van der Bijl, 1996). Its high cellulose content and the relatively high productivity (Amaducci et al., 2000) make hemp an interesting annual crop for the production of second generation bio-ethanol. The analysis of different growing conditions has shown flowering to be a key stage for the subsequent fibre or biomass yield (in terms of both quantity - Van der Werf et al., 1994, 1996; Struik et al., 2000 - and quality - Venturi and Amaducci, 1999; Keller et al., 2001; Mediavilla et al., 2001; Amaducci et al., 2005, 2008b). Given this link between optimal harvesting time and flowering, a model that would correctly estimate the time of flowering over a wide range of agro-ecological conditions differing in temperature and daylength

\footnotetext{
* Corresponding author. Tel.: +39 0523 599223; fax: +39 0523599222.

E-mail address: stefano.amaducci@unicatt.it (S. Amaducci).
}

would be useful for strategic decisions regarding optimal sowing time and cultivar choice.

Because of the large agro-ecological range in which hemp can be grown (Dewey, 1913) with differences in temperature and daylength but also in terms of available (irrigation) water there are many options to choose planting date and cultivars of different duration and photoperiod sensitivity. Such decisions could be supported with a model that quantifies the effects of air temperature and photoperiod on the time to $50 \%$ flowering. Past studies on modelling hemp phenology have evaluated the timing of emergence and flowering in growth chamber experiments and on a limited number of cultivars (Lisson et al., 2000a,b). Field-grown crops undergo diurnal fluctuating temperatures and gradually changing day lengths something not normally simulated in growth cabinets, a difference known to make extrapolation of the latter problematic (e.g. White et al., 2005). Amaducci et al. (2008a), improving on concepts of Lisson et al. (2000a,b), proposed a new model to estimate time between emergence and flowering in field-grown hemp cultivars. The model requires a relatively small set of parameters of a set of non-linear equations that describe the individual effect of air temperature (beta function) and photoperiod (switch-off function). The model was calibrated and validated using data sets from multiple years and 
sowing times for a single location (Cadriano, Northern Italy). In general the model satisfactorily reproduced observed differences in the flowering dates of a range of cultivars - Carmagnola, Felina 34, Fibranova, Futura and Tiborszallasi - over the tested range of air temperature-day length conditions (Amaducci et al., 2008a).

The collection of data on time between emergence and flowering in field studies across Europe carried out within the EU project Hemp Sys (http://www.hempsys.net) offered an opportunity to evaluate the model of post-emergence hemp phenology over a much wider range of air temperatures and photoperiods. Purpose of this study is to assess the validity of the hemp phenology model of Amaducci et al. (2008a) against datasets from a range of latitudes in Europe and determine possible application limits. It is known that models in general perform better in conditions close to those used during model building, testing and calibration (e.g. Oreskes et al., 1994). For phenology models it will be most challenging to test whether prediction of time to flowering is still possible when the photoperiod conditions are close to those prohibiting flowering (at higher latitudes for hemp). On the other hand phenology may be influenced by other factors than temperature and photoperiod. Especially drought tends to have variable effects ranging from reducing to enhancing time to $50 \%$ flowering dependent on the severity of the stress (Clarkson and Russell, 1976; Mahalakshmi and Bideinger, 2008). As the model does not use a hydro-thermal-time concept (Graziani and Steinmaus, 2008) it may prove difficult to predict under the more extreme climates in the Mediterranean agroecologies.

Due to its robustness and adaptability hemp is well suited to the central European climate. It is fast growing (more than $3 \mathrm{~m}$ in 100 days), gives a large biomass yield despite modest fertilization and has no requirement for agrochemicals whatsoever. It leaves the cultivated land free of weeds and aerated which benefits successive crops. Indeed it can be grown under an organic regime.

Compared to other crops, hemp yields a relatively high regional added value. Storage, processing and in most cases further steps of the process chain usually take place close to where crops are grown. This reduces the costs and increases its environmental credibility. According to the Ernst and Young report for the EU Commission (cited in Karus, 2006), hemp as well as flax leads to more regional employment per hectare than wheat. On a perspective of a larger diffusion in the near future of hemp for biomass production, the need of tools (e.g. simulation models) to predict the potential of cultivation for different environments is clear.

In this context the proposed model could be easily implemented in a decision support system (DSS) to explore and identify the cultivation conditions allowing the largest cultivation window (from planting to flowering) ensuring a satisfactory production

\section{Materials and methods}

\subsection{The hemp phenology model}

Post-emergent hemp phenology is divided into three phases: the basic vegetative phase (BVP), the photoperiod induction phase $(P I P)$, and the flower development phase (FDP). The latter ends when $50 \%$ of plants in a stand flower.

Full description of the model is given in the seminal paper (Amaducci et al., 2008a). Here follows a summary description only. In the model, the thermal and photo-thermal time is converted into fractional developmental rates $\left(R_{d e v}(x), \mathrm{d}^{-1}\right)$. Accumulated
Table 1

Phenological parameters and standard errors estimated at Cadriano (Italy) for different cultivars (Amaducci et al., 2008a). $T_{b}$ : base air temperature for development; $T_{0}$ : optimal air temperature at which the maximum rate of development occurs; $T_{c}$ : ceiling air temperature at which development ceases; $K(\mathrm{~h})$ : switch-off photoperiod at which the photoperiodic factor is $50 \%$ of the maximum; $n$ : shape parameter of the photoperiodic factor; $D_{x}$ : number of days needed to complete the respective developmental stages under optimal climatic conditions $(x=1,2,3$ to indicate $B V P$, PIP and FDP, respectively); ND: not determined.

\begin{tabular}{|c|c|c|c|c|}
\hline \multirow[t]{2}{*}{ Cultivar } & \multicolumn{4}{|c|}{ Basic vegetative phase $(B V P)$} \\
\hline & $T_{b}\left({ }^{\circ} \mathrm{C}\right)$ & $T_{0}\left({ }^{\circ} \mathrm{C}\right)$ & $T_{c}\left({ }^{\circ} \mathrm{C}\right)$ & $D_{1}$ (No. of days) \\
\hline Felina 34 & \multirow{4}{*}{$1.9 \pm 0.4$} & \multirow{4}{*}{$26.4 \pm 0.1$} & \multirow{4}{*}{$40.0 \pm 0.2$} & $13.2 \pm 0.4$ \\
\hline Fibranova & & & & $23.6 \pm 0.6$ \\
\hline Futura & & & & $19.7 \pm 0.3$ \\
\hline Tiborszallasi & & & & $18.5 \pm 1.0$ \\
\hline \multirow[t]{2}{*}{ Cultivar } & \multicolumn{4}{|c|}{$\begin{array}{l}\text { Photo-inductive phase (thermal parameters as for the } \\
\text { flowering development phase) }\end{array}$} \\
\hline & $K(\mathrm{~h})$ & $n$ & & $D_{2}$ (No. of days) \\
\hline Felina 34 & \multicolumn{3}{|c|}{$47.0 \pm 0.7$} & \\
\hline Fibranova & \multirow{3}{*}{$14.1 \pm \sim$} & $61.9=$ & & \\
\hline Futura & & $52.1=$ & & 1 \\
\hline Tiborszallasi & & $66.7=$ & & \\
\hline \multirow[t]{2}{*}{ Cultivar } & \multicolumn{4}{|c|}{ Flowering development phase (FDP) } \\
\hline & $T_{b}\left({ }^{\circ} \mathrm{C}\right)$ & $T_{o}\left({ }^{\circ} \mathrm{C}\right)$ & $T_{c}\left({ }^{\circ} \mathrm{C}\right)$ & $D_{3}$ (No. of days) \\
\hline \multicolumn{5}{|l|}{ Felina 34} \\
\hline Fibranova & \multirow{2}{*}{$11.3 \pm 0.3$} & \multirow{2}{*}{$26.4 \pm 0.1$} & \multirow{2}{*}{$40.0 \pm 0.2$} & \multirow{2}{*}{$4.7 \pm 0.5$} \\
\hline $\begin{array}{l}\text { Futura } \\
\text { Tiborszallasi }\end{array}$ & & & & \\
\hline
\end{tabular}

fractional development is calculated as follows during the three phases until reaching unity:

$R_{\text {dev }}(x)=\mid \begin{array}{ll}\frac{f T(1)}{D_{1}} & x=1 \\ \frac{f T(2) \cdot f P}{D_{2}} & x=2 \\ \frac{f T(3)}{D_{3}} & x=3\end{array}$

where $D_{x}$ (physiological developmental days) indicates the number of days needed to complete the respective phenological phase under optimal conditions ( $x=1,2,3$ to indicate BVP, PIP and FDP, respectively); $f T$ (Eq. (2)) and $f P$ (Eq. (3)) represent the thermal and photoperiodic factor, respectively. The duration of $P I P$ was assumed to be 1 day for optimal air temperature and day length conditions.

The rate of change in development in response to air temperature $(f T(x))$ is nonlinear with initial quasi-exponential to linear response reaching an optimum after which the rate declines steeply (beta function, Yin et al., 2003, 1995; Yan and Hunt, 1999)

$f T(x)[x=1,2,3]=\mid \begin{array}{ll}0 & T \leq T_{b}, T \geq T_{c} \\ \frac{T_{c}-T}{T_{c}-T_{o}} \cdot\left(\frac{T-T_{b}}{T_{o}-T_{b}}\right)^{\left(T_{o}-T_{b}\right) /\left(T_{c}-T_{o}\right)} & T_{b}<T<T_{c}\end{array}$

where $T\left({ }^{\circ} \mathrm{C}\right)$ is the mean hourly air temperature, $T_{b}\left({ }^{\circ} \mathrm{C}\right)$ is the base air temperature for development, $T_{C}\left({ }^{\circ} \mathrm{C}\right)$ is the ceiling air temperature at which development ceases, $T_{o}\left({ }^{\circ} \mathrm{C}\right)$ is the optimal air temperature at which the maximum rate of development occurs.

A sigmoid, switch-off function was used as a photoperiodic factor $(f P)$ to model the response to day length:

$f P=\frac{K^{n}}{K^{n}+P^{n}}$

where $P(\mathrm{~h})$ is the day length, $K(\mathrm{~h})$ and $n$ are the parameters setting the switch-off point (day length giving $f P=0.5$ ) and the cultivarspecific photoperiod sensitivity, respectively.

Table 1 reports the parameter values estimated in the earlier work to characterize single cultivars and phases. 
Table 2

Treatment information for field trials carried out at Cadriano (Northern Italy), Catania (Southern Italy), Jokioinen (Finland) and Wageningen (The Netherlands) and used for the calibration and validation of the hemp phenology model from Amaducci et al. (2008a). Var: varietal trial; M: multiple-sowing trial; D: sowing density trial; N: nitrogen fertilization trial.

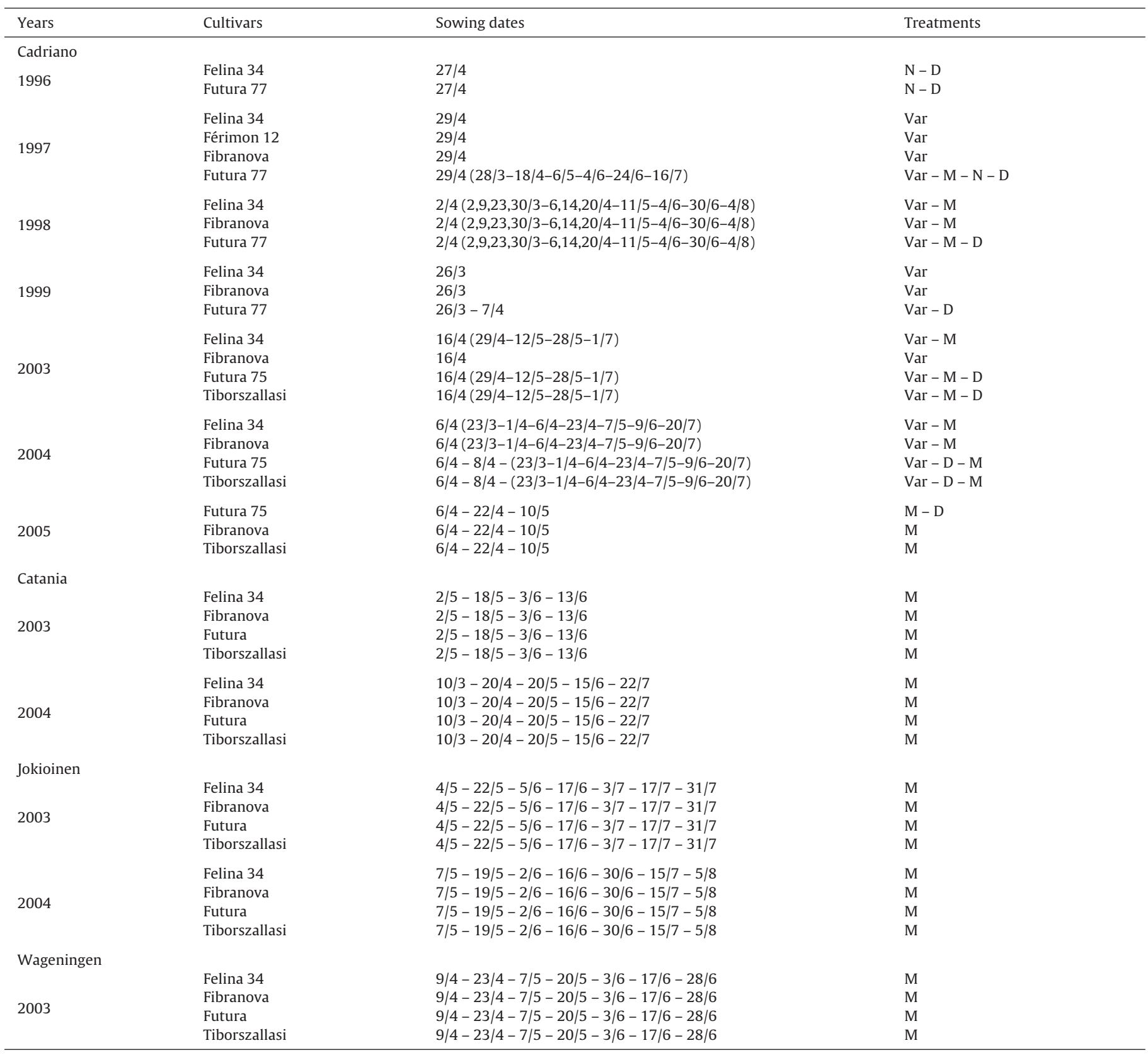

\subsection{Database generation}

Phenological datasets were collected in the years 1996-1999 and 2003-2005 from separate field trials (Table 2), conducted as part of both Italian (Ranalli, 2002) and Europe wide (Cromack et al., 1997; Amaducci, 2003) studies. Trials were carried out at Cadriano, Northern Italy (latitude: $44^{\circ} 33^{\prime}$ North; longitude: $11^{\circ} 21^{\prime}$ East), Catania, Southern Italy (latitude: $37^{\circ} 28^{\prime}$ North; longitude: $15^{\circ} 06^{\prime}$ East), Jokioinen, Finland (latitude: $60^{\circ} 49^{\prime}$ North; longitude: $23^{\circ} 29^{\prime}$ East), and Wageningen, The Netherlands (latitude: $52^{\circ} 00^{\prime}$ North; longitude: $5^{\circ} 67^{\prime}$ East).

The model was run using onsite collected meteorological data and phenological data from four hemp cultivars of different origin, sexual type and maturity group: Fibranova, Italian origin, dioecious sexual type, late maturity group; Felina 34, French origin, monoecious sexual type, medium maturity group; Futura, French origin, monoecious sexual type, medium-late maturity group; Tiborszallasi, Hungarian origin, dioecious sexual type, medium-late maturity group. De Meijer (1995) provides a review of origin, breeding history, registration, availability and agronomic features of the cultivars used in this study.

Planting conditions varied widely, ranging from early March at Italian sites (low air temperatures and short, increasing day length) to early August at both Cadriano and Jokioinen (high air temperatures and extended decreasing day length). In particular, the crops were planted both before and after the summer solstice, thus encountering either increasing or decreasing day lengths. Sources of variation (i.e. plant density, nitrogen supply) were randomized in split-split plot: minimal sub-sub plot size was $50 \mathrm{~m}^{2}$. The interested reader may refer to Amaducci 
(1998) and Amaducci et al. (2002) for details on the field trials.

The model uses air temperature records (as a proxy of plant temperatures). Hourly or daily (maximum and minimum) values of air temperature were supplied for the years of interest by weather stations positioned in the vicinity of the field trials. Missing hourly values of air temperature were estimated from daily minimum and maximum temperatures using the model proposed by Campbell (1985). Day length was calculated on the basis of solar geometry, the latitude of the site and the day of the year (Spitters et al., 1986).

Counts of flowering plants were carried out on 20-50 plants per plot. A minimum of one count per week was made, while frequency was increased near and during flowering up to a count every two days. For both monoecious and dioecious genotypes a plant was recorded as flowering when anthers and/or stigma were visible. The time between beginning and end of flowering differed between trials (up to 60 days from the appearance of the first to the last flower). As discussed in Amaducci et al. (2008a), the date when 50\% of plants had visible flowers was selected as the temporal reference point for all flowering observations. The spread in time from sowing to emergence was about seven days within experiments. Modelling of the time of crop emergence was outside the scope of this work. For this reason, all simulations started on the date of actual $50 \%$ emergence as determined during field inspections.

\subsection{Model calibration and evaluation}

For each cultivar, the database of phenological observations was split into two datasets (I, II). To determine model parameters a calibration dataset (dataset I) was created using the calibration set from Cadriano that was also used for the previous paper (years 1996-1999 and 2003-2004, Amaducci et al., 2008a) as well as one year of data (selected at random) from each of the other sites. Dataset II (validation data set) contained the remaining data, to be used for model validation.

The choice to use a large amount of data in the calibration process was made to increase the robustness of the estimated parameters.

Calibration of the model parameters was carried out according to the same procedure as described by Amaducci et al. (2008a). In particular, average common values were given to parameters showing similar values across all cultivars in the course of preliminary calibration runs. With the exception of physiological developmental days for PIP (parameter $D_{2}$ set equal to 1 ), model parameters were estimated via calibration against observed dates from dataset I, by using the Gauss-Newton algorithm that minimizes the square error of estimation (routine lsqnonlin of MATLAB ${ }^{\circledR}$, http://www.mathworks.com). The $95 \%$ C confidence bounds for fitted coefficients were computed with the MATLAB ${ }^{\circledR}$ function nlparci, which uses the formula:

$C=b \pm t \sqrt{S}$

where $b$ is the array of the coefficients produced by the fit, $t$ is the inverse of Student's $t$ cumulative distribution function at 0.95 probability and $S$ is a vector of the diagonal elements from the covariance matrix of the coefficient estimates. Standard error associated to each optimized parameter was estimated as a square root of $S$ using $t=2$ as an approximation of the inverse Student's $t$-distribution.

The agreement between the model outputs and field observations was evaluated by the inspection of time series (durations of phases between events). Further evaluation was performed via elementary statistics (mean, standard error, simple deviation) and the following performance indices: percent relative root mean square error, RRMSE (Eq. (5)); modelling efficiency, $E F$ (Eq. (6)); coefficient of residual mass, CRM (Eq. (7)) (Loague and Green, 1991):

$$
\begin{aligned}
& \text { RRMSE }=\frac{1}{\bar{O}} \cdot \sqrt{\frac{\sum_{i=1}^{N}\left(E_{i}-O_{i}\right)^{2}}{N}} \times 100 \\
& E F=1-\frac{\sum_{i=1}^{n}\left(E_{i}-O_{i}\right)^{2}}{\sum_{i=1}^{n}\left(O_{i}-\bar{O}\right)^{2}} \\
& C R M=\frac{\sum_{i=1}^{n} O_{i}-\sum_{i=1}^{n} E_{i}}{\sum_{i=1}^{n} O_{i}}
\end{aligned}
$$

where $E$ is the estimated value, $O$ is the observed value, $\bar{O}$ is the mean of the observed values, $i$ is the $i$ th $E / O$ pair, and $n$ is the number of $E / O$ pairs. $R R M S E$ ranges from 0 (best) to positive infinity. $E F$ can give either positive or negative values, 1 being the upper limit, while negative infinity is the theoretical lower boundary. Negative values of $E F$ indicate that the model introduces more ambiguity than that introduced by simply using the mean value of the observations as an estimator. CRM can be either positive (under-estimation) or negative (over-estimation), 0 being the optimal value. Dedicated libraries provided with the tool IRENE_DLL (Fila et al., 2003) were used for computing these performance indices.

\section{Results}

\subsection{Air temperature, day length and irradiance conditions}

The distributions of daily minimum and maximum air temperatures during the growing season (averaged across the years available for each site) are shown in Fig. 1. The crops experienced higher summer air temperatures at Italian sites than in other locations but, on average, mean air temperature tended to remain below $30^{\circ} \mathrm{C}$. Both early- and late-season frosts are a possibility at the Northern latitudes. At Jokioinen the hemp crops were damaged by frost in both years and respectively on 3/9/2003 and 10/10/2004.

The day length patterns showed marked differences along the cropping cycle among sites (Fig. 1). Day length was as short as $11 \mathrm{~h}$ in March at Italian sites to then peak at $18.8 \mathrm{~h}$ achieved at summer solstice in Jokioinen. The summer solstice value of $14.6 \mathrm{~h}$ at Catania is close to the optimum photoperiod ( $\sim 14 \mathrm{~h})$ estimated for hemp by Amaducci et al. (2008a) and other authors (Borthwick and Scully, 1954; Lisson et al., 2000b). In contrast, the summer is marked by long days in Finland, inhibitory to hemp flower induction (see observed and modelled flowering dates in Section 3.3).

\subsection{Model parameterisation}

Parameter estimates for effects of air temperature and photoperiod are reported in Table 3. Fig. 2 shows the beta-function temperature response from the estimated parameters of $B V P$ and FDP. Some discrimination among cultivars is possible, based on the $B V P$ duration under optimum conditions (parameter $D_{1}$ ). The greatest value of $D_{1}$ was found for cultivar Fibranova (23 days) and the lowest value was found for cultivar Felina 34 ( $\sim 11$ days). Differences among cultivars are also found in the shape parameter $(n)$ of the photo-inductive phase, with a clear distinction between cultivars Fibranova as the most sensitive cultivar to sub-optimal day lengths ( $n \sim 43)$, and the least sensitive Felina $34(n \sim 33)$. Fig. 3 displays the photoperiodic response of the four cultivars for a range of day lengths.

Excluding the trials where $50 \%$ of flowering did not occur because of early frost (Section 3.3), model calculations using the parameter values estimated from the calibration set roughly matched the observed phase durations for both the calibration and 

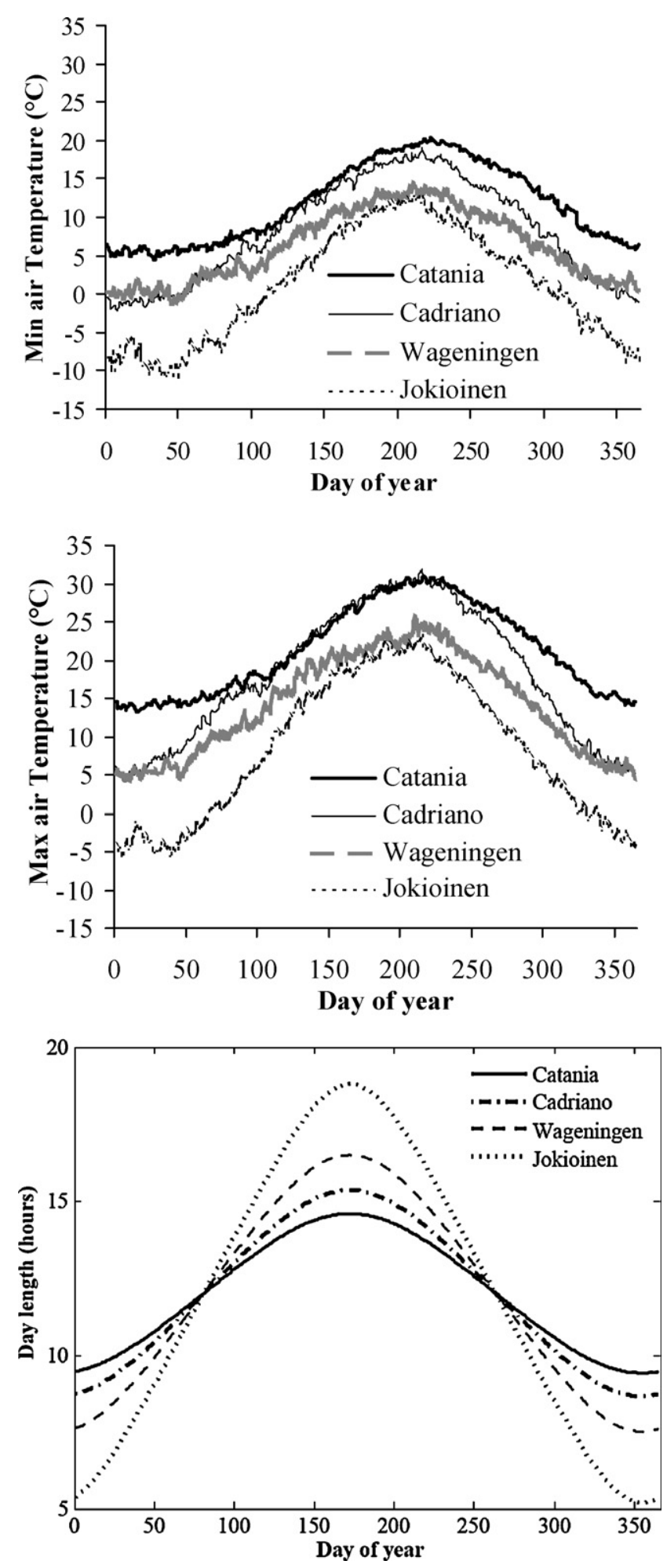

Fig. 1. Long-term average daily maximum and minimum air temperatures registered at different sites and the pattern of calculated yearly day lengths.

the validation data sets (Fig. 4). Both graphs show residuals (estimates minus measured data) lining up around zero. Spreads are apparent, but with no sizeable systematic deviations.

\subsection{Observed dates and modelled phases}

A selection of flowering patterns as observed in the broad range of conditions from the experiments and showing worst and best

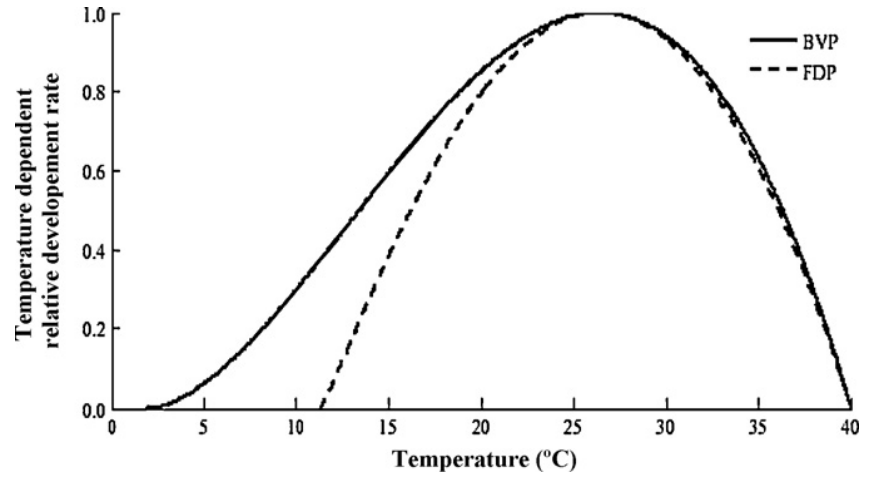

Fig. 2. Beta function for response of the relative development rate to temperature for the basic vegetative phase $(B V P)$ and the flowering development phase (FDP). The response for the photo-inductive period (PIP) shows the same trend as the BVP.

fits is given in Fig. 5 (calibration dataset) and Fig. 6 (validation dataset), including the phase lengths estimated by the model and the periods between first flowering plant and end of flowering (all plants flowering). For all cultivars flowering is rarely observed in the long-day conditions of Jokioinen, where only early-planted Felina 34 and Futura are likely to flower. Over the range of tested environments, large differences in the time elapsed from emergence to $50 \%$ of flowering were observed. The range in durations between emergence and $50 \%$ flowering were comparable for Felina 34 and Tiborszallasi (from 11 to 116 days and from 24 to 128 days respectively), while the range was wider for the other cultivars. The flowering pattern was heterogeneous, depending on cultivar, year, planting time and location. For example, flowering dates of Felina 34 indicate that this cultivar flowered earlier when planting was earlier (and vice versa) at Cadriano (Fig. 6) but not at Wageningen (Fig. 5). Flowering times of Futura crops grown at Cadriano were related to planting dates in 2004 (Fig. 6) but not in 2003 (Fig. 5). At Catania, flowering dates of both Fibranova and Tiborszallasi indicated a direct relationship to sowing times (Figs. 5 and 6), but this is not the case at Wageningen (Fig. 6).

Estimated and actual number of days from emergence to $50 \%$ of flowering corresponded reasonably well for both calibration and validation data sets as evidenced by the statistics presented in Table 4 . The overall amount of error was relatively low $(R R M S E<20 \%)$, modelling efficiency was high $(E F>0.75)$, and the model tended to neither over-estimate nor under-estimate time between emergence and $50 \%$ flowering as indicated by the balance between positive and negative values of CRM. A large difference between observations and estimates was obtained with Fibranova

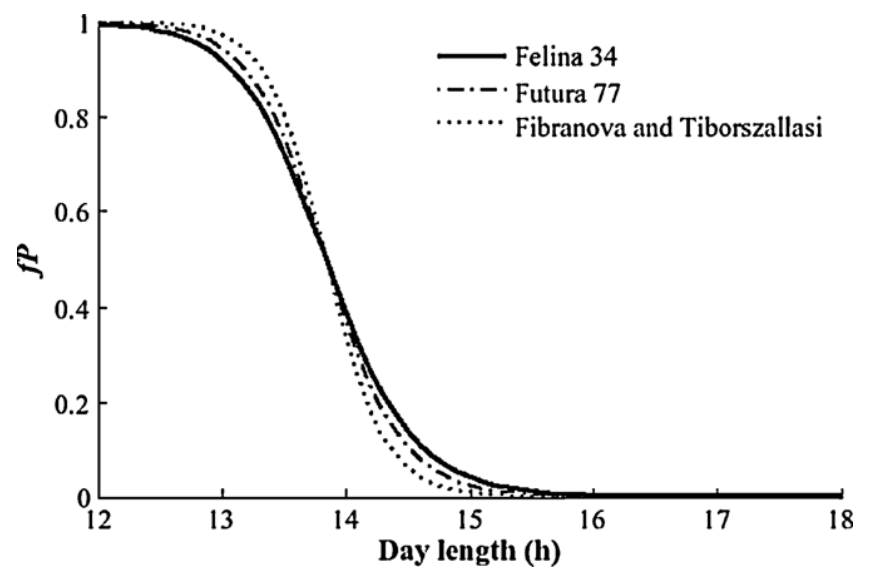

Fig. 3. Estimated photoperiodic factor $(f P)$ for the reduction of development rate as a function of day length for four tested cultivars. 
Table 3

Phenological parameters and standard errors estimated for different cultivars based on data sets from multiple years and sites (see text). For explanation of symbols see caption of Table 1.

\begin{tabular}{|c|c|c|c|c|c|}
\hline \multirow[t]{2}{*}{ Cultivar } & \multicolumn{5}{|c|}{ Basic vegetative phase } \\
\hline & $T_{b}\left({ }^{\circ} \mathrm{C}\right)$ & \multicolumn{2}{|c|}{$T_{o}\left({ }^{\circ} \mathrm{C}\right)$} & $T_{c}\left({ }^{\circ} \mathrm{C}\right)$ & $D_{1}$ (No. of days) \\
\hline Felina 34 & \multirow{4}{*}{$0.4 \pm 0.7$} & \multirow{4}{*}{\multicolumn{2}{|c|}{$27.6 \pm 0.2$}} & \multirow{4}{*}{$41.3 \pm \sim 0.0$} & $11.1 \pm 0.4$ \\
\hline Fibranova & & & & & $23.0 \pm 0.6$ \\
\hline Futura & & & & & $14.7 \pm 0.3$ \\
\hline Tiborszallasi & & & & & $20.6 \pm 1.2$ \\
\hline \multirow[t]{2}{*}{ Cultivar } & \multicolumn{5}{|c|}{$\begin{array}{l}\text { Photo-inductive phase (thermal parameters as for the } \\
\text { basic vegetative phase) }\end{array}$} \\
\hline & \multicolumn{2}{|l|}{$K(\mathrm{~h})$} & \multicolumn{2}{|l|}{$n$} & $D_{2}$ (No. of days) \\
\hline Felina 34 & \multirow{4}{*}{\multicolumn{2}{|c|}{$13.7 \pm \sim 0.0$}} & \multicolumn{2}{|c|}{$33.4 \pm 0.7$} & \multirow{4}{*}{1} \\
\hline Fibranova & & & \multicolumn{2}{|c|}{$42.8 \pm 0.6$} & \\
\hline Futura & & & 39. & 0.6 & \\
\hline Tiborszallasi & & & 38. & 1.7 & \\
\hline \multirow[t]{2}{*}{ Cultivar } & \multicolumn{5}{|c|}{ Flowering development phase } \\
\hline & $T_{b}\left({ }^{\circ} \mathrm{C}\right)$ & $T_{o}$ & & $T_{c}\left({ }^{\circ} \mathrm{C}\right)$ & $D_{3}$ (No. of days) \\
\hline \multicolumn{6}{|l|}{ Felina 34} \\
\hline Fibranova & \multirow{2}{*}{$12.3 \pm 0.5$} & \multirow{2}{*}{\multicolumn{2}{|c|}{$27.6 \pm 0.2$}} & $41.3 \pm \sim 0.0$ & $2.6 \pm 0.3$ \\
\hline Futura & & & & $41.01-0.0$ & $2.0 \pm 0.0$ \\
\hline
\end{tabular}

(28 days under-estimation with the second sowing date at Catania in 2004) and Felina 34 (33 days under-estimation with the first sowing date at Jokioinen in 2003).

The thermal requirements computed with the beta function indicate differences between cultivars (Table 5) which reflect the differences observed in parameter $D_{1}$ estimates (Table 3 ). In number of days, the estimated average duration of $B V P$ was shortest for Felina 34 (19 days) and longest for Fibranova (39 days). The duration of the FDP was estimated to be less than one week for all cultivars. Average duration of the PIP was $\sim 44$ days for Futura and Fibranova, and $\sim 32$ and $\sim 36$ for Felina 34 and Tiborszallasi respectively.

Profile plots of a simulation study with 5-day time step for experiments with four or more sowing dates (Fig. 7) show that the overall effects of sowing time in different years and for different sites are estimated rather well. The trends in both the simulated and actual number of days elapsed from emergence to $50 \%$ of flowering show how the combined effect of temperature and photoperiod turns into complex non-linear responses that vary widely between sites, complexity of responses being especially observed for cultivars Felina 34 and Futura at Cadriano (middle latitude). At this site, the time between emergence and flowering in reaction to changes in sowing dates differed from that of the other cultivars. The cycle length of the two monoecious cultivars tends to get longer as the emergence date is postponed until the point (about mid-May with Felina 34, and end of April with Futura) where it shortens with further postponement. For the other cultivars, the cycle length decreases uniformly with emergence date until it reaches a minimum level. Cultivar differences in the profile plot are less evident at Wageningen. At Jokioinen, $50 \%$ of flowering was not reached by late-sown monoecious cultivars, whereas dioecious cultivars were able to complete the cycle only once (Tiborszallasi in the first sowing time of 2003) at such northern latitude.

The simulated time between emergence and flowering, deviated most from observations for cultivars Felina 34 and Futura at the extreme latitudes.

The simulated data presented in Fig. 7 can be used to calculate the minimum and maximum time-span between emergence
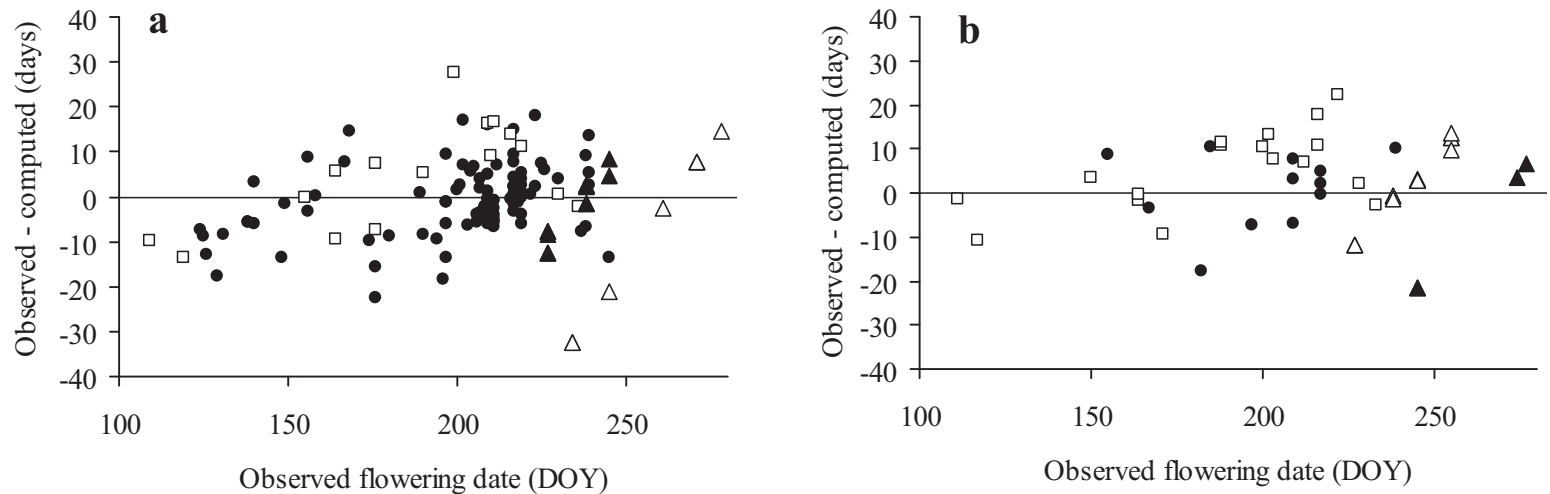

Fig. 4. Scatterplots of differences between estimated and measured time between emergence and $50 \%$ flowering, for the calibration (a) and the validation (b) data sets. Data where $50 \%$ of flowering (estimated or observed) was not reached are not shown. Symbols represent data for Cadriano (closed circles), Catania (open squares), Jokioinen (open triangles) and Wageningen (closed triangles).

\section{Table 4}

Basic statistics (number of data, mean, standard error) and indices of agreement between estimated and actual durations from emergence to 50\% of flowering (RRMSE, relative root mean square error; $E F$, modelling efficiency; $C R M$, coefficient of residual mass), computed on both the calibration and the validation data sets.

\begin{tabular}{|c|c|c|c|c|c|c|c|c|c|}
\hline \multirow[t]{2}{*}{ Data set } & \multirow[t]{2}{*}{ Cultivar } & \multirow[t]{2}{*}{ Number of data ${ }^{a}$} & \multicolumn{2}{|c|}{ Actual } & \multicolumn{2}{|c|}{ Estimated } & \multirow[t]{2}{*}{ RRMSE (\%) } & \multirow[t]{2}{*}{$E F$} & \multirow[t]{2}{*}{ CRM } \\
\hline & & & Mean & Standard error & Mean & Standard error & & & \\
\hline \multirow{4}{*}{ Calibration } & Felina 34 & 39 & 59 & 4.3 & 61 & 4.7 & 18.289 & 0.835 & -0.027 \\
\hline & Fibranova & 39 & 86 & 5.2 & 92 & 5.6 & 12.533 & 0.886 & -0.073 \\
\hline & Futura & 56 & 78 & 3.5 & 80 & 3.6 & 16.558 & 0.750 & -0.024 \\
\hline & Tiborszallasi & 19 & 71 & 6.6 & 79 & 7.7 & 16.996 & 0.797 & -0.066 \\
\hline \multirow{4}{*}{ Validation } & Felina 34 & 10 & 40 & 5.1 & 38 & 5.1 & 16.065 & 0.822 & 0.062 \\
\hline & Fibranova & 7 & 68 & 8.0 & 70 & 11.2 & 14.416 & 0.796 & 0.002 \\
\hline & Futura & 14 & 62 & 7.6 & 69 & 9.8 & 22.018 & 0.750 & -0.104 \\
\hline & Tiborszallasi & 12 & 67 & 8.8 & 73 & 11.2 & 12.249 & 0.905 & -0.032 \\
\hline
\end{tabular}

a Data for treatments for which $50 \%$ of flowering (either estimated or observed) was not achieved were left out of the calculation. 


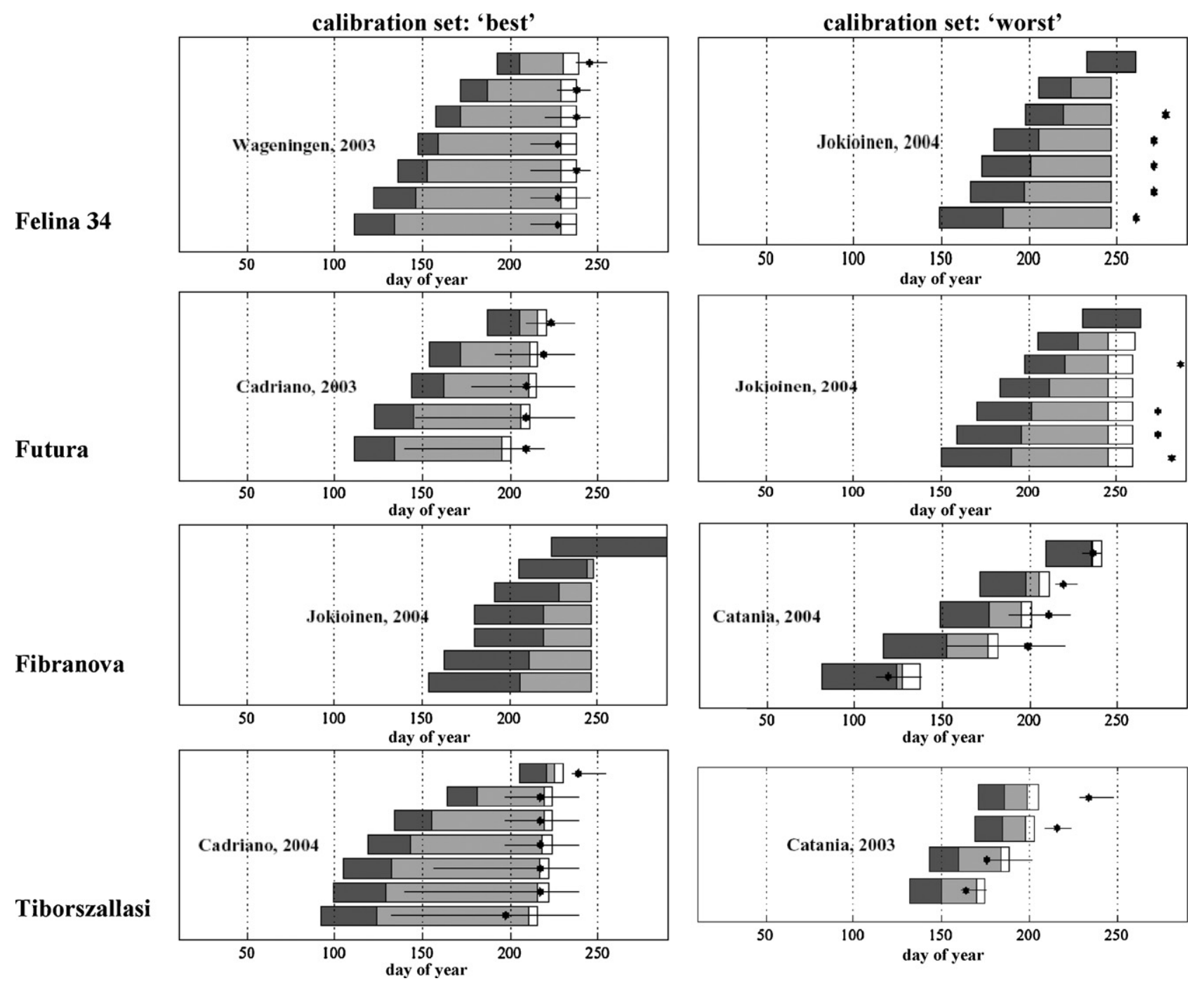

Fig. 5. Estimated phase durations (bars), and observed dates of $50 \%$ of flowering (black dots) for the calibration dataset. Dark grey bars: basic vegetative phase; light grey bars: photo-inductive phase; open bars: flowering development phase. Horizontal lines through the data points indicate the period between appearance of the first and the last flowering plant. Absence of black dots indicates that no flowering plants were observed during field inspections.

and flowering. For the given locations and meteorological conditions results are given in Table 6. For all cultivars the extension of period emergence-flowering seems to vary according to latitude with the highest values at high latitude, Jokioinen, cultivar Futura (152.4 days) to the lowest at low latitude, Catania, cultivar Felina 34 (16.6 days). These differences are attenuated if thermal time of growing degree days (GDD) are considered instead of chronological time or days. The longest thermal time was accumulated by

Table 5

Mean estimated thermal time $\left({ }^{\circ} \mathrm{Cd}\right)$ and days for completion of each phase in different cultivars (minimum and maximum requirements are in brackets).

\begin{tabular}{lccl}
\hline Cultivar & BVP & PIP & FDP \\
\hline Estimated degree-days $\left({ }^{\circ} \mathrm{Cd}\right)$ & & \\
Felina 34 & 305.8 & $505.5(31.1-1394.6)$ & 72.4 \\
Fibranova & 635.5 & $886.4(28.6-1538.2)$ & 72.4 \\
Futura & 406.8 & $804.5(32.1-1430.6)$ & 72.4 \\
Tiborszallasi & 566.2 & $697.3(36.5-1340.3)$ & 72.4 \\
Estimated days & & & \\
Felina 34 & $19.4(11.9-32.6)$ & $32.1(1.7-92.6)$ & $6.1(2.8-15.8)$ \\
Fibranova & $35.3(24.9-53.9)$ & $43.7(1.4-83.6)$ & $3.9(2.8-9.1)$ \\
Futura & $25.3(15.8-39.8)$ & $44.5(1.5-88.7)$ & $5.3(2.9-22.3)$ \\
Tiborszallasi & $29.6(22.1-43.3)$ & $35.9(1.5-81.3)$ & $3.8(2.8-6.9)$ \\
\hline
\end{tabular}

Fibranova at Cadriano (2116 GDD), the shortest remains Felina 34 at Catania (411 GDD). At high latitude (Jokioinen and Waganingen) the influence of cultivar has less influence on cycle length than at lower latitude (Cadriano and Catania). This is particularly evident at Wageningen where the variability of the cycle length falls within the range 131-139 days, for the maximum, and 35-48 for the minimum, while at Cadriano and Catania differences among cultivars are larger: 60-133 (maximum values at Cadriano) and 26-56 (maximum values at Catania). Late flowering cultivars as Fibranova and Tiborszallasi never reached flowering before September frost would kill the crop at the high latitude of Jokioinen.

\section{Discussion}

The model to simulate time between emergence and flowering proposed by Amaducci et al. (2008a) was found to simulate well flowering times for four hemp cultivars grown over a wide range of latitudes. The parameter values had to be slightly changed (compare Table 3 versus Table 1 ), hence the model with the here presented parameter values can be expected to perform well at sites not currently included in calibration or validation. The largest divergence was found in photoperiodic sensitivity ( $n$ : ranging from 33.4 to 42.2 in Table 1 and from 47.0 to 66.7 in 


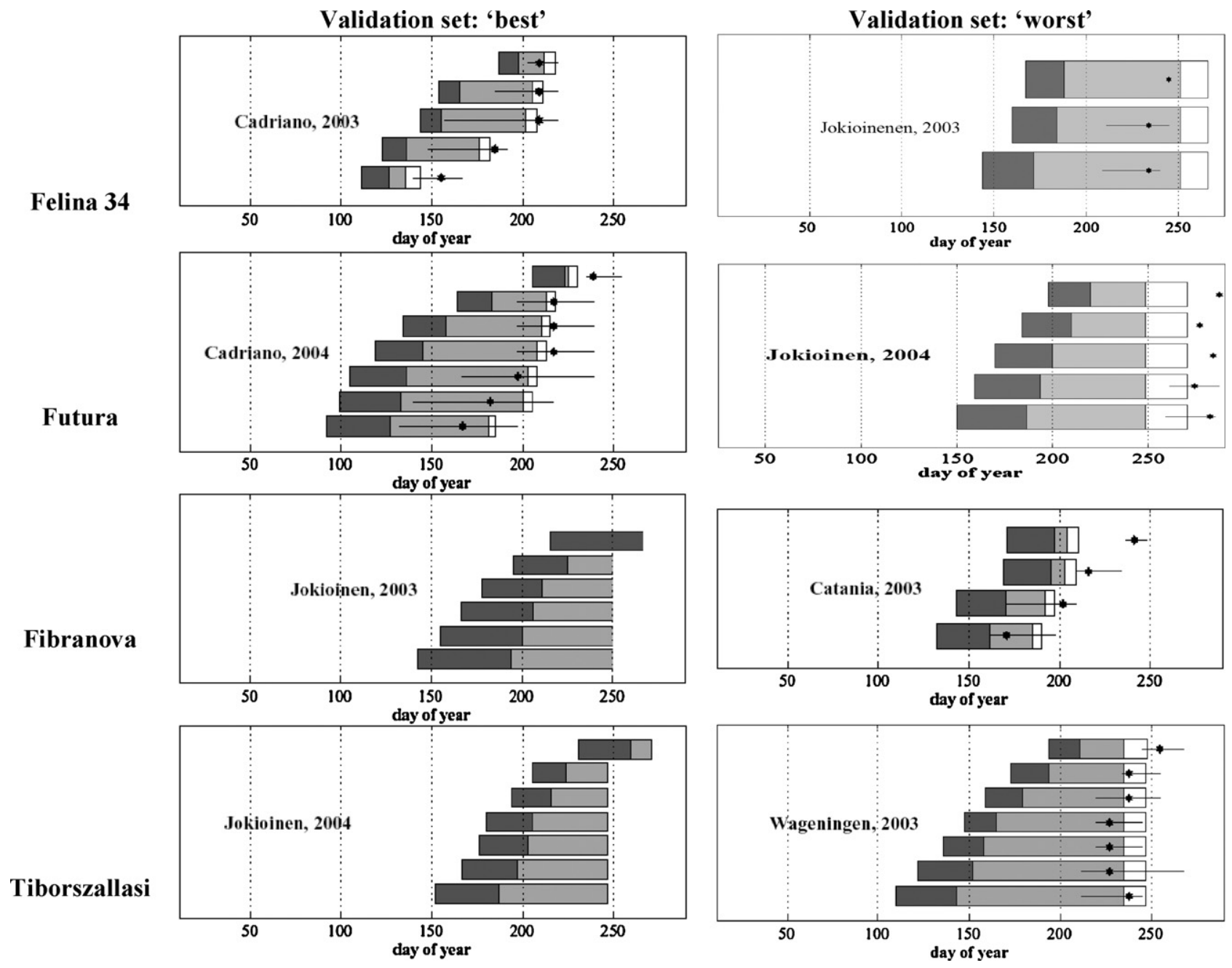

Fig. 6. Estimated phase durations (bars), and observed dates of $50 \%$ of flowering (black dots) for the validation dataset. Dark grey bars: basic vegetative phase; light grey bars: photo-inductive phase; open bars: flowering development phase. Horizontal lines through the data points indicate the period between appearance of the first and the last flower. Absence of black dots indicates that no flowering plants were observed during field inspections.

Table 2), however the sensitivity to this parameter is relatively low (Amaducci et al., 2008a). For thermal parameters characterizing all development phases, the only remarkable difference was $\mathrm{Tb}$ for the $B V P$ which was $1.9{ }^{\circ} \mathrm{C}$ and it is now $0.4{ }^{\circ} \mathrm{C}$. The estimated degree-days for the BVP ranging between $306^{\circ} \mathrm{Cd}$ (Felina 34) and $636^{\circ} \mathrm{Cd}$ (Fibranova) are situated around the values given by Lisson et al. (2000b) for cultivars Futura and Kompolti (383 and $390^{\circ} \mathrm{Cd}$ respectively with a base temperature of $1^{\circ} \mathrm{C}$ ), and essentially

Table 6

Simulated maximum and minimum time-span of the period emergence-flowering (days) for the four cultivars and localities. The corresponding emergence day of year (DOY) is also reported.

\begin{tabular}{|c|c|c|c|c|c|c|c|}
\hline \multirow[t]{2}{*}{ Cultivar } & \multirow[t]{2}{*}{ Locality } & \multicolumn{3}{|l|}{ Maximum } & \multicolumn{3}{|l|}{ Minimum } \\
\hline & & Emer. (DOY) & Emer.-Flower. (days) & GDD & Emer. (DOY) & Emer.-Flower. (days) & GDD \\
\hline \multirow{4}{*}{ Felina 34} & Jokioinen & 128 & 135.4 & 1118.6 & 218 & 51.6 & 432.7 \\
\hline & Wageningen & 103 & 131.2 & 1802.9 & 203 & 34.7 & 649.8 \\
\hline & Cadriano & 133 & 60.5 & 1349.4 & 218 & 17.8 & 432.9 \\
\hline & Catania & 133 & 26.2 & 540.8 & 228 & 16.6 & 410.9 \\
\hline \multirow{4}{*}{ Fibranova } & Jokioinen & - & - & - & - & - & - \\
\hline & Wageningen & 103 & 138.8 & 2065.9 & 208 & 47.5 & 753.8 \\
\hline & Cadriano & 78 & 132.9 & 2116.4 & 213 & 30.8 & 743.7 \\
\hline & Catania & 108 & 55.7 & 956.3 & 228 & 29.7 & 736.2 \\
\hline \multirow{4}{*}{ Futura } & Jokioinen & 118 & 152.4 & 1217.0 & 213 & 56.4 & 540.7 \\
\hline & Wageningen & 108 & 131.5 & 1916.4 & 208 & 37.7 & 622.0 \\
\hline & Cadriano & 103 & 98.7 & 1704.7 & 218 & 21.8 & 521.6 \\
\hline & Catania & 123 & 39.9 & 696.8 & 223 & 20.4 & 510.7 \\
\hline \multirow{4}{*}{ Tiborszallasi } & Jokioinen & - & - & - & - & - & \\
\hline & Wageningen & 103 & 135.6 & 2030.3 & 203 & 43.7 & 751.1 \\
\hline & Cadriano & 98 & 109.3 & 1853.9 & 218 & 28.1 & 669.4 \\
\hline & Catania & 103 & 49.2 & 763.5 & 213 & 26.7 & 672.3 \\
\hline
\end{tabular}


Felina 34 (Calibration)
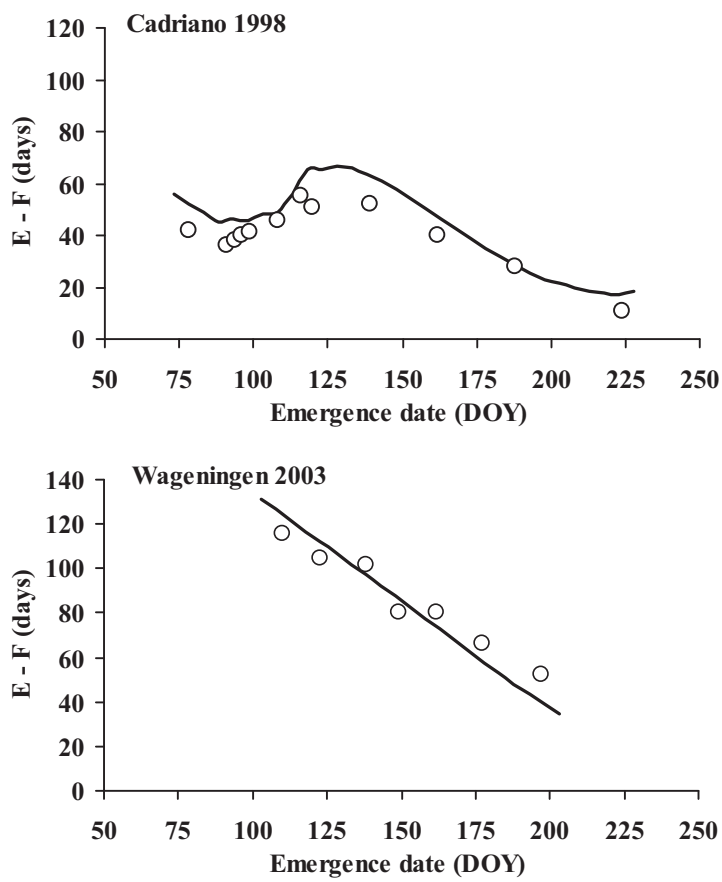

Fibranova (Calibration)

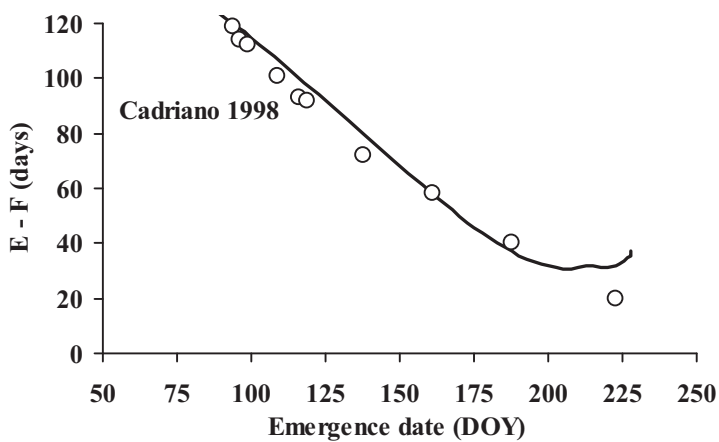

Futura (Calibration)
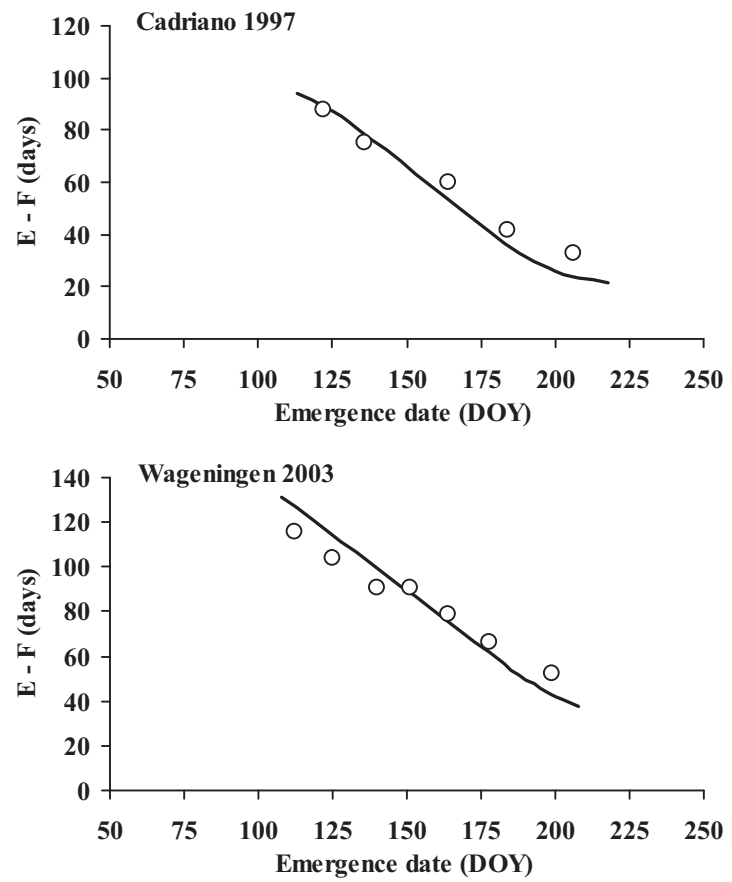

Tiborszallasi (Calibration)

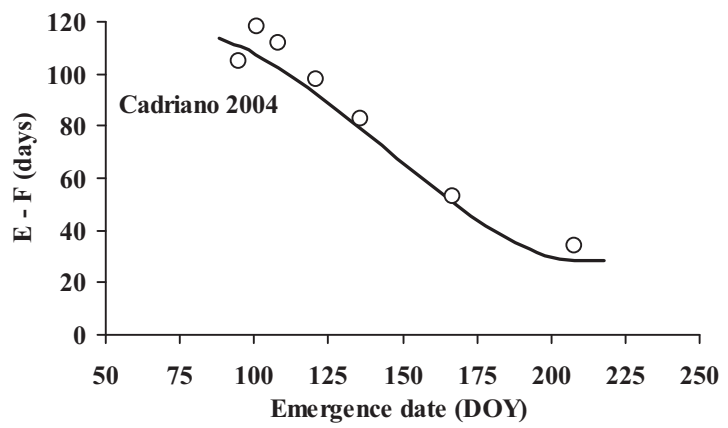

Fig. 7. Plots of simulated (lines) and actual (open circles) time between emergence and $50 \%$ flowering (E-F) against day of the year (DOY), for calibration data.

correspond to the findings of Amaducci et al. (2008a). Different values of parameter $D_{1}$ play a role in determining the length of the $B V P$ and, as a consequence, the moment when the PIP starts. For short $B V P$ cultivars (e.g. Felina), plants from early or medium-early spring sowings start the PIP before the summer solstice, and therefore start flowering before the 21st of June. On the contrary, cultivars with a long BVP (e.g. Fibranova), reach the PIP at times later than the summer solstice. This was observed to happen with many sowing dates.

Although for most parameters the difference between values obtained with only the Cadriano data and the values obtained including also Catania, Jokioinen and Wageningen were minimal, differences in time to flowering estimates were indeed observed when the parameterization achieved at Cadriano was used to run to model at the other sites (data not shown). This shows that caution is needed when using this phenology model to estimate times of flowering at sites clearly outside the calibration range.

The analysis of the economic viability of hemp production over the full potential growing area in Europe using a decision support system depends on accurate simulation of the flowering date over a wide range of environmental conditions. According to the statistics of Table 4, the model estimated plant flowering with reasonable accuracy but, despite this general conclusion, shortcomings in the model emerged that should be improved in the future. For instance the need of further study to better understand plant-light interactions, especially in their intensity-duration aspects, is an aspect that the model does not take into consideration. Plants normally adapt to changing light intensity by a variety of physiological adjustments. It is known that plant aerial development is affected by light intensity (e.g. Cremer et al., 1998; Cookson and Granier, 2006), with a broad range of responses among genotypes (Chenu et al., 2004). Thus, the combined effects of photoperiod and light intensity in addition to photoperiod per se may be responsible for changes in the rate of plant development, as shown for buckwheat where flowers appear sooner with high irradiance (Quinet et al., 2004).

Another possible explanation for discrepancies between observed and calculated values can be the heterogeneous nature of the genotypes used, which may produce unpredictable interactions with local conditions.

The results presented in this paper provide the limits of accuracy within which the model of post-emergent hemp phenology 
may be used to gauge performance of hemp cultivation, as influenced by air temperature and photoperiod. What are acceptable limits of accuracy depend on the user needs, and the type of management practices being used (i.e. sowing date and cultivar type). The model appears to be more appropriate to estimate hemp flowering dates at medium latitudes in Europe (Cadriano, Northern Italy; Wageningen, The Netherlands) than at extreme ones. The most southerly site (Catania, Southern Italy) was difficult to simulate especially in the last two sowing dates in 2003. These last ones experienced a period of water stress due to lack of water for irrigation which might have delayed flowering. As this environment is characterized by regular periods of extreme water and temperature stresses it may be outside the validity domain of the model. The correct simulation of hemp flowering under water stress conditions prevalent in the Mediterranean basin must be ascertained before making attempts at modelling hemp phenology at other sites where water stress occurs regularly. Current data sets lack information on within-season total water content in the soil profile so additional experimenting is needed for more rigorous testing and improvement of the model. This investigation has used generic optimized parameters, which over multiple years provide values of general use for potentially any application. The spatial application of the model is limited by the ability to provide appropriate site-representative parameters that also capture the temporal variability within seasons. The problems registered at Catania do indeed suggest that a local specific parameterization may be required for some cultivars, to improve the estimation accuracy at each site. Specific locations may have characteristics which cause the parameters to deviate from a general model, but a method of model optimization for each site has additional problems. Restrictions in data availability and noise in available datasets place real limits on what can be accomplished using the model discussed here. Essentially such deviation is an indication of the omission of locally relevant processes from the model and a search for and inclusion of these processes seems more relevant than local parameterization.

Improvements in the accuracy of flowering date estimations e.g. including the effect of cultivation practices and water stress - will eventually fulfil the goal for the model to serve as a decision support system for hemp production. In such respect, only limited information is available in the literature for hemp about the effect on fibre quality features of variation (anticipation or postponement) in the harvest time. Preliminary results from the Hemp Sys project indicate that harvest delays of about 10 days from the optimal moment can affect fibre yield and characteristics for textile destination (Westerhuis et al., 2009). In this regard, mean deviations (observed minus computed time to 50\% of flowering) were 6.5 (Cadriano), 11.1 (Catania), 17.1 (Jokioinen), and 6.6 (Wageningen) days. The smallest deviations were obtained for cultivar Felina 34, and with this cultivar, the deviations were within the suggested limit of 10 days at all sites. Similar performances to those obtained with Felina 34 were observed with cultivar Futura, with the exception of Jokioinen (15.9 days mean deviation). The incidence of model failures was somehow higher for late flowering cultivars (Fibranova and Tiborszallasi). A point of remark here is that major uncertainties tend to be associated with long plant cycles, especially when the crops are sown early and plants flower after the summer solstice. On average, $84.6 \%, 57.6 \%, 40.0 \%$ and $67.8 \%$ of model simulations fell within the range of 10 days at Cadriano, Catania, Jokioinen and Wageningen, respectively ( $73.8 \%$ being the mean value for all simulations). These results cannot be considered satisfactory (especially for Jokioinen) from the viewpoint of decision support system for tactical management, but for strategical decision the model performances seems useful. The experimental layout in this study includes several trials (and the related simulations) with sowing dates largely outside the time window of agronomic relevance for fibre production. This allows to use the data shown in Table 6 to be used as basis for several agronomic considerations. At high latitudes, if the production targets is quality fibre (which is maximised after flowering), the use of late flowering cultivars as Fibranova and Tiborszallasi should be discouraged given the uncertainty whether the flowering stage will be reached. More appropriate are Felina and Futura which ensure a large cultivation window (more than 130 days) with chances to provide good quality fibre. At Wageningen (and generally in the conditions at middle latitudes in Europe) the possibilities are wider. First of all, the phenological behaviour is not heavily influenced by the cultivar (see also Fig. 7) and for early sowing (around DOY 100) growing cycles are larger than 130 days. This permits planting date to be chosen: (1) for maximum biomass accumulation with hemp as principal crop, planting date after mid of April and harvest at the end of August; and (2) after a spring crop with short cycle (e.g. processing peas) which should leave the soil free for a late hemp sowing in the first ten days of July and harvest by half September.

In Italy, the differences among cultivars are larger, especially at Cadriano. The choice of an appropriate sowing date is critical for the early flowering cultivar Felina 34: sowing in April results in a longer growing cycle and therefore higher biomass yield, while a more traditional sowing time (mid-March) results in a short vegetative period with limited biomass accumulation which would allow the cultivation of a second crop after hemp. The longest growing cycle, ensuring the highest biomass production in North Italy are achieved with late cultivars such as Fibranova, that should be planted early in March.

In very southern conditions (Sicily, Catania) the possibilities of a successful crop are limited by very inductive flowering conditions forcing hemp to exhibit rather short cycles, even with late cultivars as Fibranova or Tiborzallasi. In these environment planting should be planned taking into account water availability and the tendency of all genotypes to precocious flowering when sown in March.

This model was a first attempt to quantify the effect of temperature and day length on hemp phenology over a large range of latitudes. A few modifications in the design of new experiments (e.g. by including the effect of irradiance levels) would help reduce sources of variation and increase the accuracy in the calibrated values. Such modifications could be brought by controlled-environment studies. In addition, more frequent measurements (every second day) during the flowering time would have given more accurate information about $50 \%$ flowering as temporal reference point (Amaducci et al., 2008c).

\section{Conclusion}

Considering that hemp harvesting for specific applications should be performed at flowering, it is essential to integrate hemp phenology prediction in decision support of cultivation practices. The accuracy of prediction of days to $50 \%$ of flowering observed in this model study is an indication that there is potential to model crop phenology under varying conditions. The evaluation of the model's performance using data sets from different sites and growing seasons showed reasonable agreement between estimated and observed values of emergence and 50\% flowering dates in hemp in several but not all cases. Improvement in understanding the modelled processes could take benefit of controlled-environment studies, where the model functions will provide the basis for further improvement towards accounting for other factors than the ones considered so far. The level of accuracy obtained with the model is satisfactory for strategic decision regarding sowing and harvesting time and cultivar choice, but no tactical decisions (e.g. time of harvest based on flowering time) can be accurately supported. 


\section{Acknowledgements}

This research was carried out under the auspices of the European Commission; project Hemp Sys (http://www.hempsys.net). The authors would like to acknowledge all people involved in the difficult and time-consuming operation of flowering counts.

\section{References}

Amaducci, S., 1998. Analisi dell'accrescimento e dello sviluppo in canapa da fibra (Cannabis sativa L.). PhD Thesis. University of Bologna, Italy.

Amaducci, S., 2003. HEMP-SYS: design, development and up-scaling of a sustainable production system for HEMP textiles - an integrated quality SYStem approach. J. Ind. Hemp 8, 79-83.

Amaducci, S., Amaducci, M.T., Benati, R., Venturi, G., 2000. Crop yield and quality parameters of 4 annual fibre crops (Hemp, Kenaf, Maize and Sorghum) in the North of Italy. Ind. Crops Prod. 17, 179-186.

Amaducci, S., Errani, M., Venturi, G., 2002. Plant population effects on fibre hemp morphology and production. J. Ind. Hemp 7, 33-60.

Amaducci, S., Pelatti, F., Medeghini Bonatti, P., 2005. Fibre development in hemp (Cannabis sativa L.) as affected by agrotechnique: preliminary results of a microscopic study. J. Ind. Hemp 10, 31-48.

Amaducci, S., Colauzzi, M., Bellocchi, G., Venturi, G., 2008a. Modelling post-emergen hemp phenology (Cannabis sativa L.): theory and evaluation. Eur. J. Agron. 28 , 90-102.

Amaducci, S., Zatta, A., Pelatti, F., Venturi, G., 2008b. Influence of agronomic factors on yield and quality of hemp (Cannabis sativa L.) fibre and implication for an innovative production system. Field Crop. Res. 107, 161-169.

Amaducci., S., Colauzzi, M., Zatta, A., Venturi, G., 2008c. Flowering dynamics in monoecious and dioecious hemp genotypes. J. Ind. Hemp 13 (1), 5-19.

Biewinga, E.E., van der Bijl, G., 1996. Sustainability of energy crops in Europe. A methodology developed and applied. Centre for Agriculture and Environment, Utrecht, The Netherlands, p. 209.

Borthwick, H.A., Scully, N.J., 1954. Photoperiodic responses of hemp. Bot. Gaz. 116 14-29.

Campbell, G.S., 1985. Soil physics with BASIC: transport models for soil-plant systems. Elsevier Science Publishers, New York, The Netherlands, p. 150.

Chenu, K., Franck, N., Dauzat, J., Lecoeur, J., 2004. Modelling the phenotypic variability of rosette architecture of Arabidopsis thaliana in several ecotypes and mutants in response to incident radiation. In: 4th International Workshop on Functional-Structural Plant Models, 7-11 June, Montpellier, France, pp. 360-364.

Clarkson, N.M., Russell, J.S., 1976. Effect of water stress on the phasic development of annual Medicago species. Aust. J. Agric. Res. 27 (2), 227-234.

Cookson, S.J., Granier, C., 2006. A dynamic analysis of the shade-induced plasticity in Arabidopsis thaliana rosette leaf development reveals new components of the shade-adaptative response. Ann. Bot. 97, 443-452.

Cremer, F., Havelange, A., Saedler, H., Huijser, P., 1998. Environmental control of flowering time in Antirrhinum majus. Physiol. Plantarum 104, 345-350.

Cromack, H.T.H., Bruce, D.M., von Drach, V., Hague, J., Marvin, H.J.P., Kessler, R.W. Nebel, K., Struik, P.C., Venturi, G., Amaducci, S., 1997. The hemp for Europe manufacturing and production systems project. Objectives and initial results. In: Scientific Communication at the Bioresources Hemp Conference, 27 February-2 March, Frankfurt am Main, Germany.

De Meijer, E., 1995. Fibre hemp cultivars: a survey of origin, ancestry, availability and brief agronomic characteristics. J. Int. Hemp Ass. 2, 66-73.
Dewey, L.H. 1913. Hemp. USDA Yearbook, pp. 283-346.

Fila, G., Bellocchi, G., Donatelli, M., Acutis, M., 2003. IRENE_DLL: object-oriented library for evaluating numerical estimates. Agron. J. 95, 1330-1333.

Graziani, A., Steinmaus, S.J., 2008. Hydrothermal and thermal time models for the invasive grass, Arundo donax. Aquat. Bot. 90 (1), 78-84

Karus, M., 2002. European hemp industry 2001: cultivation, processing and product lines. J. Ind. Hemp 7, 95-99.

Karus, M., 2006. Official founding of the "European Industrial Hemp Association (EIHA)" and Third International Hemp Conference. J. Ind. Hemp 11 (2), 69-72.

Keller, A., Leupin, M., Mediavilla, V., Wintermantel, E., 2001. Influence of the growth stage of industrial hemp on chemical and physical properties of the fibres. Ind. Crops Prod. 13, 35-48.

Lisson, S.N. Mendham, N. Carberry, P.S. 2000a Development of a hemp (Cannabis sativa $\mathrm{L}$.) simulation model. 1. General introduction and the effect of temperature on the pre-emergent development of hemp. Austr. J. Exp. Agric. 40, 405-411.

Lisson, S.N., Mendham, N.J., Carberry, P.S., 2000b. Development of a hemp (Cannabis sativa L.) simulation model. 2 . The flowering response of two hemp cultivars to photoperiod. Austr. J. Exp. Agric. 40, 413-417.

Loague, K., Green, R.E., 1991. Statistical and graphical methods for evaluating solute transport models: overview and application. J. Contam. Hydrol. 7, 51-73.

Mahalakshmi, V., Bideinger, 2008. Flowering response of pearl millet to water stress during panicle development. Ann. Appl. Biol. 106 (3), 571-578.

Mediavilla, V., Leupin, M., Keller, A., 2001. Influence of the growth stage of industrial hemp on the yield formation in relation to certain fibre quality traits. Ind. Crops Prod. 13, 49-56.

Oreskes, N., Shrader-Frechette, K., Belitz, K., 1994. Verification, validation and confirmation of numerical models in the earth sciences. Science 263, 641-646.

Quinet, M., Cawoy, V., Lefèvre, I., van Miegroet, F., Jacquemart, A.-L., Kinet, J.-M., 2004 Inflorescence structure and control of flowering time and duration by light in buckwheat (Fagopyrum esculentum Moench). J. Exp. Bot. 55, 1509-1517.

Ranalli, P., 2002. Hemp in Italy: a new research project. J. Ind. Hemp 7, 139-141.

Spitters, C.J.T., Toussaint, H.A.J.M., Goudriaan, J., 1986. Separating the diffuse and direct component of global radiation and its implications for modeling canopy photosynthesis. Part I. Components of incoming radiation. Agric. Forest Meteorol. 38, 217-229.

Struik, P.C., Amaducci, S., Bullard, M.J., Stutterheim, N.C., Venturi, G., Cromack, H.T.H., 2000. Agronomy of fibre hemp (Cannabis sativa L). Ind Crops Prod. 11, 107-118.

Van der Werf, H.M.G., Haasken, H.J., Wijlhuizen, M., 1994. The effect of day length on yield and quality of fibre hemp (Cannabis sativa L.). Eur. J. Agron. 3, 117-123.

Van der Werf, H.M.G., Mathijssen, E.W.J.M., Haverkort, A.J., 1996. The potential of hemp (Cannabis sativa L.) for sustainable fibre production: a crop physiological appraisal. Ann. Appl. Biol. 129, 109-123.

Venturi, G., Amaducci, M.T., 1999. Le colture da fibra. Ed agricole, ISBN: 88-2064288-3.

Westerhuis, W., Amaducci, S., Struik, P.C., Zatta, A., van Dam, J.E.G., Stomph, T.J. 2009. Sowing density and harvest time affect fibre content in hemp (Cannabis sativa L.) through their effects on stem weight. Ann. Appl. Biol. 155 (2) 225-244.

White, J.W., Hoogenboom, G., Hunt, A.L., 2005. A structured procedure for assessing how crop models respond to temperature. Agron. J 97, 426-439.

Yan, W., Hunt, L.A., 1999. An equation for modelling the temperature response of plants using only the cardinal temperatures. Ann. Bot. 84, 607-614.

Yin, X., Kropff, M.J., McLaren, G., Visperas, R.M., 1995. A nonlinear model for crop development as a function of temperature. Agric. Forest Meteorol. 77, 1-16.

Yin, X., Goudriaan, J., Lantinga, E.A., Vos Jan Spiertz, H.S., 2003. A flexible sigmoid function of determinate growth. Ann. Bot. 91, 361-371. 